\title{
Knowledge on Hospital Waste Management among Senior Staff Nurses Working in a Selected Medical College Hospital of Bangladesh
}

\author{
Mohammad Nasir Uddin, ${ }^{1}$ Mohammad Rashedul Islam, ${ }^{2}$ and Khadiza Yesmin ${ }^{3}$ \\ ${ }^{1}$ Faridpur Nursing Institute, Faridpur 7800, Bangladesh \\ ${ }^{2}$ Research \& Training Monitoring Department, Bangladesh College of Physicians and Surgeons (BCPS), Dhaka 1212, Bangladesh \\ ${ }^{3}$ Musapur Union Sub-Center, Raipura, Narsingdi 1630, Bangladesh
}

Correspondence should be addressed to Mohammad Rashedul Islam; mrislam96@gmail.com

Received 2 April 2014; Accepted 25 July 2014; Published 17 August 2014

Academic Editor: David Bolzonella

Copyright (c) 2014 Mohammad Nasir Uddin et al. This is an open access article distributed under the Creative Commons Attribution License, which permits unrestricted use, distribution, and reproduction in any medium, provided the original work is properly cited.

\begin{abstract}
Background. Healthcare wastes include all types of wastes generated by healthcare establishments. Waste disposal problem is growing with an ever-increasing number of hospitals, clinics, and diagnostic laboratories in Bangladesh and also in Faridpur town. Aim and Objective. The outcomes of this study will contribute to increase proper waste management practice among nurses in Bangladesh. Methods. A descriptive type of cross sectional study design was used to assess the level of knowledge regarding hospital waste management among senior staff nurses working in Faridpur Medical College Hospital, Bangladesh. All respondents ( $n=125)$ were selected by random sampling. Results. In the answer of knowledge about general waste only $4 \%(n=5)$ gave all correct answers. In the answer of knowledge about infectious waste $63.2 \%(n=79)$ gave one correct answer, of knowledge about pharmaceutical waste only $8 \%(n=10)$ gave all correct answers, and of knowledge about biomedical waste only $7.2 \%(n=9)$ gave all correct answers. In the answer of knowledge about color coded bins collecting waste $53.6 \%(n=67)$ cannot give any correct answer and only $46.4 \%$ $(n=58)$ gave all correct answers and of knowledge about the safe disposal of hospital waste $16 \%(n=8)$ could not give any correct answer. However, against all questions were 5 options. Conclusion. Knowledge about hospital waste and its management is very poor among senior staff nurses. As a recommendation to improve this situation continuous training should be made compulsory for healthcare personnel specially staff nurses working in Bangladesh.
\end{abstract}

\section{Introduction}

Healthcare wastes pose a serious public health problem. It is essential for proper management [1].

Healthcare wastes include all types of wastes generated by healthcare establishments, research facilities, and laboratories $[2,3]$.

There are various estimates regarding hazardous and nonhazardous constituents of healthcare waste. According to World Health Organization (WHO) related reports and studies, around $85 \%$ of hospital wastes are nonhazardous, $10 \%$ are infectious (biologically hazardous), and the remaining $5 \%$ are toxic chemicals, pharmaceutical, and radioactive wastes [2].
This traditional estimate, however, is not consistent for many developing countries. The proportion for hazardous waste varied from country to country: Pakistan about 20\%, Nigeria 26.5\%, and in Sub-Saharan African countries about $2-10 \%$. In Bangladesh, $36.03 \%$ in diagnostic centers and higher clinics; and about $50 \%$ in urban health centers of Tanzania constituted hazardous waste [4].

Healthcare service providers generally aim at controlling and preventing diseases such as communicable ones. However, in the course of activities, the generation of hazardous and nonhazardous waste is a concern of an environmental risk to healthcare workers, the public and the environment at large [4]. 
In developing countries, the quantity of healthcare waste has sharply risen in recent years as a result of rapid population growth, thus increasing the demand for health services [5].

In 1995, the regional office of South-East Asia of the World Health Organization (WHO) made a survey of healthcare waste management in 9 countries in the region with substantial responses from Indonesia, Myanmar, Srilanka, Thailand, and Bangladesh. Result of the survey showed that most healthcare establishments do not have any waste management plan or procedure. In several countries there is no legislation at all. There is also a lack of waste management guidelines [6].

For effective waste management, legislation on incinerator plants to integrate pollution control was introduced by the European Commission in 1995. After 1996 the European Commission turned their attention to waste minimization by reuse, recycling, segregation, and better management with minimum impact on the environment and ecosystem. They are imposing strict laws to manage and control hospital waste. In the European countries the majority of wastes are incinerated with stringent control of air pollution. There is a move from local incineration toward regional medical waste incinerators with better air pollution-control characteristics [6].

In Bangladesh, there are various types of hospitals with different bed capacities. At the district level, there are both 50-150-bedded and 200-250-bedded hospitals. In some district hospitals, there are also specialized hospitals. There are 500-1150-bedded specialized hospitals either as separate hospitals or they are attached to medical college hospitals. About 3,500 metric tons of garbage are generated per day in the Dhaka city; 200 tons of which are generated by the healthcare establishments, and $20 \%$ of which are infectious wastes. The amount is increasing day by day, with the rising number of healthcare establishments. Being a poor country that has the highest population density, it is a burden on the part of the Government of Bangladesh to handle the situation both economically and technically. In urban areas, about 40$50 \%$ of the total generated wastes are collected per day by the municipal authority, while the rest remains as uncollected wastes obviously degrading the environment and creating health hazards [6].

Environmental protection Act, 1995, consensus among the owners of private clinics and the policy-makers of the government and the nongovernmental organization (NGO) is also lacking what is crucial for healthy environment in the healthcare facilities. There is a lack of waste management system in both governmental and nongovernmental healthcare facilities [6].

The segregation of wastes at the point of generation is very minimal. Most tertiary hospitals dispose of their wastes at the nearest municipal dustbins. It is also found that some medical staffs even earn some money by selling used syringes and other medical wastes. Most of the healthcare staffs are not aware of the proper management of wastes. Adequate and effective waste management facilities are absent. Besides, the budget is meagre to effectively implement safe disposal of hospital wastes [7].

In March 2009, 240 people in the Indian state of Gujarat contracted hepatitis B following medical care delivered by previously used syringes later discovered to have been acquired through the black market trade of unregulated healthcare waste [8].

The clinical staff in developing countries lacks knowledge about the transmission of hospital acquired infections caused by poor handling of healthcare waste, poor attitude of staff towards hospital discipline, and improper training of staff on HCWM (Healthcare waste management) [9].

In 2002, the results of a WHO assessment conducted in 22 developing countries showed that the proportion of healthcare facilities that do not use proper waste disposal methods ranges from $18 \%$ to $64 \%$ [10].

Hospital waste management of Bangladesh is very poor. There is lack of attention in this issue in both governmental and nongovernmental sectors. But due to the rapid increase of healthcare establishments in the country, the problem is also increasing.

As there is little research on this critical issue in Bangladesh especially in Faridpur. Those studies together with the studies carried out in different parts of the world were reviewed for the purpose of the study.

Nurses are involving wastes generation, segregation, disinfection, and so forth. They have an important role in hospital waste management. The outcomes of this study will contribute to enhance proper waste management practice among nurses in Bangladesh. It will provide baseline data for higher authority to plan for an initiation for staff development in order to improve quality of care. This study will guide the health authority in future planning of hospital waste management in Faridpur.

Safe disposal of medical waste is the important part of healthcare management. But most of healthcare establishments in Faridpur town are not following proper disposal system. The purpose of this study is to assess the existing level of knowledge regarding hospital waste management among senior staff nurses working in the healthcare establishments at Faridpur town.

\section{Methods}

A descriptive type of cross sectional study to assess the level of knowledge regarding hospital waste management was used. A semistructured questionnaire was developed to collect data. Pretesting was done in Sadar Hospital, Faridpur District. After few modifications it was finalized as a data collection tool. The study was conducted from January 2012 to June 2012. The sample frame was 145. Among them 125 samples were collected through random sampling. Response rate was $100 \%$. Necessary approvals were taken from the respective authorities of the hospital for the study. The purpose and nature of the study was introduced and briefed to the nurses. Self-administered questionnaires were distributed to the nurses to fill up to provide data. Few operational definitions were used in this study, such as the following.

(1) Senior Staff Nurse. In this study senior staff nurse means those who are working in governmental or nongovernmental hospitals after completing the 4 th year diploma in nursing. 
(2) Knowledge. In this study knowledge means information about hospital waste, classification of hospital waste, generation process, segregation process, collection procedure, transportation, incineration, dumping procedure, and safe disposal.

(3) Management. In this study management means activities involving hospital waste generation and its proper disposal according to government rules and regulations regarding hospital waste management.

(4) Hospital Waste. Hospital waste mean all wastes, biological or nonbiological, which are discarded and not intended for further use. About $85 \%$ of these wastes are actually nonhazardous wastes, $10 \%$ are infectious wastes, and $5 \%$ are noninfectious but hazardous wastes [6].

WHO recommends collecting general waste in strong black disposable plastic bags, potentially infectious hazardous healthcare waste in yellow disposable plastic bags, and used sharps in rigid containers, respectively. Black and yellow plastic-bagged wastes should be held in leak-proof bag holders. Red coloured strong leak-proof plastic bag or container capable of being autoclaved was used for highly infectious waste; brown coloured plastic bag or container was used for chemical and pharmaceutical waste. Lead box, labeled with the radioactive symbol, was used for radioactive waste $[2,11]$.

2.1. Data Analysis. Data were entered into SPSS software version 16.0. After cleaning the data recoding was done. Then according to the objective of the study data were analysed with SPSS program. Descriptive analysis was performed and finally data were presented by table.

\section{Results}

Among 125 respondents length of service of $23(18.4 \%)$ respondents was less than 5 years, of 33 (26.4\%) was 510 years, of $39(31.2 \%)$ was $10-15$ years, and of $30(24 \%)$ respondents was more than 15 years. Of all the respondents, $77(61.6 \%)$ had trained on hospital waste management, while $48(38.4 \%)$ did not have training (Table 1$)$.

In the answer of knowledge about general waste only $5(4 \%)$ gave all correct answers. More than half of the respondents did not know any information on the general waste. In the answer of knowledge about infectious waste, 79 (63.2\%) gave one correct answer; $38(30.4 \%)$ gave two correct answers, and 8 (6.4\%) gave all right answers. In the answer of knowledge about pharmaceutical waste only 10 (8\%) gave all correct answers, and of knowledge about biomedical waste only $9(7.2 \%)$ gave all correct answers (Table 2 ).

In the answers of knowledge about color coded bins collecting waste, 67 (53.6\%) could not give any correct answer and only 58 (46.4\%) gave the correct answer. In reply of the category of waste collect in "red" color coded container, 50 (40\%) could not give any correct answer and 75 (60\%) gave the correct answer. In reply of the category of waste collect in "yellow" color coded container, 105 (84\%) could not give any correct answer and $20(16 \%)$ gave the correct answer. About the category of waste collected in "black" colour coded
TABLE 1: Frequency distribution by sociodemographic characteristics of respondents.

\begin{tabular}{|c|c|}
\hline Characteristics & Frequency (percentage) \\
\hline \multicolumn{2}{|l|}{ Age } \\
\hline $25-30$ & $7(5.6)$ \\
\hline $30-35$ & $38(30.4)$ \\
\hline $35-40$ & $57(45.6)$ \\
\hline $40-45$ & $22(17.6)$ \\
\hline $45-50$ & $1(0.8)$ \\
\hline \multicolumn{2}{|l|}{ Sex } \\
\hline Male & $7(5.6)$ \\
\hline Female & $118(94.4)$ \\
\hline \multicolumn{2}{|l|}{ Marital status } \\
\hline Unmarried & $7(5.6)$ \\
\hline Married & $117(93.6)$ \\
\hline Widow & $1(0.8)$ \\
\hline \multicolumn{2}{|l|}{ Religion } \\
\hline Islam & $81(64.8)$ \\
\hline Hindu & $36(28.8)$ \\
\hline Christian & $8(6.4)$ \\
\hline \multicolumn{2}{|l|}{ Educational qualification } \\
\hline Diploma in nursing & $121(96.8)$ \\
\hline B.Sc. nursing & $4(3.2)$ \\
\hline \multicolumn{2}{|l|}{ Length of service } \\
\hline$<5$ years & $23(18.4)$ \\
\hline $5-10$ years & $33(26.4)$ \\
\hline $10-15$ years & $39(31.2)$ \\
\hline$>15$ years & $30(24)$ \\
\hline \multicolumn{2}{|l|}{ Waste management } \\
\hline Have trained & $77(61.6)$ \\
\hline Have no training & $48(38.4)$ \\
\hline
\end{tabular}

container, 40 (32\%) could not give any correct answer, and 85 $(68 \%)$ gave the right answer (Table 3 ).

In the answer of knowledge about the safe disposal of hospital waste, $8(16 \%)$ could not give any correct answer, while 97 (77.6\%) gave one correct answer, and 20 (6.4\%) gave two correct answers. In the answer of the question which types of wastes are needed for incineration, 37 (29.6\%) could not give any correct answer, while $82(65.6 \%)$ gave one correct answer and $6(4.8 \%)$ gave all correct answers. In the answer of knowledge about transport procedure of hospital waste, 106 (84.4\%) could not give any correct answer, while 19 (15.2\%) gave one correct answer. The question which types of wastes are needed for disinfection, 38 (30.4\%) could not give any correct answer, while 69 (55.2\%) gave one correct answer, and 18 (14.4\%) gave all correct answers (Table 4).

Among the respondents self-opinions 111 (88.8\%) said there was no good infrastructure for waste management; $119(95.2 \%)$ said there was no logistic supply, and 115 (92\%) respondents said there was no sufficient manpower for waste management. Result showed that proper waste management facilities were not available in the study place. 
TABLE 2: Frequency distribution of respondents about hospital waste.

\begin{tabular}{|c|c|}
\hline Characteristics & Frequency (percentage) \\
\hline \multicolumn{2}{|l|}{ Hospital waste produced by } \\
\hline Clinical care provider & $58(46.4)$ \\
\hline Patient & $32(25.6)$ \\
\hline Investigation department workers & $19(15.2)$ \\
\hline Nonclinical care provider & $0(0.0)$ \\
\hline Cleaner and supporting staff & $16(12.8)$ \\
\hline \multicolumn{2}{|l|}{ Knowledge about general waste } \\
\hline No right answer & $63(50.4)$ \\
\hline One right answer & $57(45.6)$ \\
\hline All right answers & $5(4.0)$ \\
\hline \multicolumn{2}{|l|}{ Knowledge about infectious waste } \\
\hline No right answer & $0(0.0)$ \\
\hline One right answer & $79(63.2)$ \\
\hline Two right answers & $38(30.4)$ \\
\hline All right answers & $8(6.4)$ \\
\hline \multicolumn{2}{|l|}{ Knowledge about biomedical waste } \\
\hline No right answer & $4(3.2)$ \\
\hline One right answer & $90(72.0)$ \\
\hline Two right answers & $22(17.6)$ \\
\hline All right answers & $9(7.2)$ \\
\hline \multicolumn{2}{|l|}{ Waste hazardous to public health } \\
\hline No right answer & $6(4.8)$ \\
\hline One right answer & $52(41.6)$ \\
\hline Two right answers & $27(21.6)$ \\
\hline All right answers & $40(32.0)$ \\
\hline \multicolumn{2}{|l|}{ Knowledge about sharp waste } \\
\hline No right answer & $0(0.0)$ \\
\hline One right answer & $64(51.2)$ \\
\hline Two right answers & $41(32.8)$ \\
\hline All right answers & $20(16.0)$ \\
\hline \multicolumn{2}{|l|}{ Knowledge about pharmaceutical waste } \\
\hline No right answer & $38(30.4)$ \\
\hline One right answer & $77(61.6)$ \\
\hline All right answers & $10(8.0)$ \\
\hline \multicolumn{2}{|l|}{ Knowledge about radioactive waste } \\
\hline No right answer & $26(20.8)$ \\
\hline All right answers & $99(79.2)$ \\
\hline \multicolumn{2}{|l|}{ Knowledge about liquid waste } \\
\hline No right answer & $4(3.2)$ \\
\hline One right answer & $88(70.4)$ \\
\hline All right answers & $33(26.4)$ \\
\hline \multicolumn{2}{|l|}{ Knowledge about segregate of waste } \\
\hline No right answer & $45(36.0)$ \\
\hline All right answers & $80(64.0)$ \\
\hline
\end{tabular}

\section{Discussion}

Length of service of $18.4 \%$ respondents was less than 5 years, of $26.4 \%$ was $5-10$ years, of $31.2 \%$ was $10-15$ years, and of $24 \%$ respondents was more than 15 years. Of all the respondents,
TABLE 3: Frequency distribution about colour coded bin.

\begin{tabular}{lc}
\hline Characteristics & Frequency (percentage) \\
\hline Knowledge about colour coded bin & \\
No correct answer & $67(53.6)$ \\
One correct answer & $58(46.4)$ \\
Knowledge about black colour bin & \\
Wrong answer & $40(32.0)$ \\
Correct answer & $85(68.0)$ \\
Knowledge about yellow colour bin & $105(84.0)$ \\
Wrong answer & $20(16.0)$ \\
Correct answer & \\
Knowledge about red colour bin & $50(40.0)$ \\
Wrong answer & $75(60.0)$ \\
Correct answer &
\end{tabular}

TABLE 4: Frequency distribution about transport and disposal of waste.

\begin{tabular}{lc}
\hline Characteristics & Frequency (percentage) \\
\hline Knowledge about transport procedure & \\
No correct answer & $106(84.8)$ \\
One correct answer & \\
Knowledge about safe disposal & $8(15.2)$ \\
No correct answer & $97(77.6)$ \\
One correct answer & $20(6.4)$ \\
Two correct answers & \\
Knowledge about waste needing & \\
disinfection & $38(30.4)$ \\
No correct answer & $69(55.2)$ \\
One correct answer & $18(14.4)$ \\
All correct answers & \\
Knowledge about waste needing & \\
incineration & $37(29.6)$ \\
No correct answer & $82(65.6)$ \\
One correct answer & $6(4.8)$ \\
Two correct answers &
\end{tabular}

$61.6 \%$ had trained on hospital waste management, while $38.4 \%$ did not have training. A study was conducted by Akter et al. They reported that nurses, laboratory technicians, and ayahs had no training on the handling and the disposal of medical waste. Of the 82 respondents 32 (38\%) mentioned that they did not receive any training on handling medical waste. Only seven respondents mentioned that they received training [12].

The result was not similar to our study because available training was not provided in the study place.

A study was conducted by Akter et al. They reported the respondents were also not aware of the harmful or hazardous elements of medical waste. Few respondents (23 of 110) mentioned that pathogens present in medical waste might be hazardous to human health. This result was consistent with our study [12]. 
Among the respondents, $46.4 \%$ knew that waste produced by clinical care provider during providing care is hospital waste; $25.6 \%$ knew that waste produced by patient is hospital waste; $15.2 \%$ knew that waste produced by investigation department workers is hospital waste, and $12.8 \%$ knew that waste produced by cleaner and supporting staff is hospital waste. In the answer of knowledge about general waste only $4 \%$ gave all correct answers. More than half of the respondents did not know any of the general waste. In the answer of knowledge about infectious waste $6.4 \%$ gave all right answers. In the answer of knowledge about pharmaceutical waste only $8 \%$ gave all correct answers, and of knowledge about biomedical waste only $7.2 \%$ gave all correct answers. This study was consistent with the study conducted by Khattak. Where he showed that the knowledge about HCW did not exist at all in $67 \%$ and $18 \%$ of the respondents did not have that much knowledge [13].

Among the respondents self-opinions $88.8 \%$ said there was no good infrastructure for waste management; $95.2 \%$ said there is no logistic supply, and $92 \%$ respondents said there is no sufficient manpower for waste management. Result showed that proper waste management facilities were not available in the study place. This study was consistent with the study conducted by Visvanathan and Adhikari on healthcare waste management in South Asia. They reported that healthcare waste management in South Asia is an impending disaster [11].

In Bangladesh, an estimated 255 tons of medical waste is generated in Dhaka every day. Most of which is dumped in municipal bins [14].

\section{Conclusion}

Knowledge about hospital waste and its management is very poor among senior stuff nurses. As they have no sufficient knowledge regarding hospital waste storage and disposal so they cannot manage it efficiently. Actually the aim of this study was to identify where the gap is. This study highlights this issue. As a recommendation to improve this situation continuous training should be made compulsory for healthcare personnel specially nursing staff working in Bangladesh. Strict implementation of biomedical waste management rules is the need of the hour. It should be made compulsory for healthcare facilities to get their healthcare personnel trained from accredited training centers. These training sessions should not become merely a one-time activity but should be a continuous process depending upon the patient's input in different healthcare facilities. Training of sanitary staff should be specially emphasized.

\section{Conflict of Interests}

The authors declare that there is no conflict of interests regarding the publication of this paper.

\section{References}

[1] M. M. Hassan, S. A. Ahmed, K. A. Rahman, and T. K. Biswas, "Pattern of medical waste management: existing scenario in
Dhaka City, Bangladesh," BMC Public Health, vol. 8, article 36, 2008.

[2] A. Pruss, E. Giroult, and P. Rushbrook, Safe Management of Wastes from Health-Care Activities, World Health Organization, Geneva, Switzerland, 1999.

[3] S. Habibullah and S. Afsar, "Waste disposal of government health-care facilities in urban area of karachi-a kap survey," Pakistan Journal of Medical Research, vol. 46, no. 1, pp. 1-4, 2007.

[4] M. Azage and A. Kumie, "Healthcare waste generation and its management system: the case of health centers in West Gojjam Zone, Amhara Region, Ethiopia," Ethiopian Journal of Health Development, vol. 24, no. 2, pp. 119-126, 2010.

[5] E. Tesfahun, A. Kumie, W. Legesse, H. Kloos, and A. Beyene, "Assessment of composition and generation rate of healthcare wastes in selected public and private hospitals of Ethiopia," Waste Management \& Research, vol. 32, no. 3, pp. 215-220, 2014.

[6] K. Nessa and M. A. Quaiyum, Barkat-e-Khuda . Waste Management in Healthcare Facilities: A Review. ICDDR,B Working Paper No. 144.

[7] A. Biswas, A. S. M. Amanullah, and S. C. Santra, "Medical waste management in the tertiary hospitals of Bangladesh: an empirical enquiry," ASA University Review, vol. 5, no. 2, pp. 149158, 2011.

[8] K. E. Solberg, "Trade in medical waste causes deaths in India," The Lancet, vol. 373, no. 9669, p. 1067, 2009.

[9] R. Kumar, E. A. Khan, J. Ahmed, Z. Khan, M. Magan, and M. I. Mughal, "Healthcare waste management (HCWM) in Pakistan: current situation and training options.," Journal of Ayub Medical College, Abbottabad, vol. 22, no. 4, pp. 101-105, 2010.

[10] http://www.who.int/mediacentre/factsheets/fs281/en/.

[11] C. Visvanathan and R. Adhikari, "Healthcare Waste Management in South Asia," in Proceedings of the Promoting Reduce, Reuse and Recycle in South Asia. Synthesis Report of $3 R$ South Asia Expert Workshop, pp. 45-67, Kathmandu, Nepal, 2006.

[12] N. Akter, A. M. R. Chowdhury, and N. M. Kazi, Hospital Waste Disposal in Bangladesh with Special Reference to Dhaka City and Its Environmental Evaluation, Special Publication no. 87, ICDDR,B, 1999.

[13] F. H. Khattak, "Hospital Waste Management in Pakistan," Pakistan Journal of Medical Research, vol. 48, no. 1, pp. 19-23, 2009.

[14] M. M. Rahman and M. A. Ali, "Healthcare Waste management and environmental pollution in Bangladesh," in Proceedings of the International Conference on Bangladesh Environment (ICBEN '00), Dhaka, Bangladesh, January 2000. 

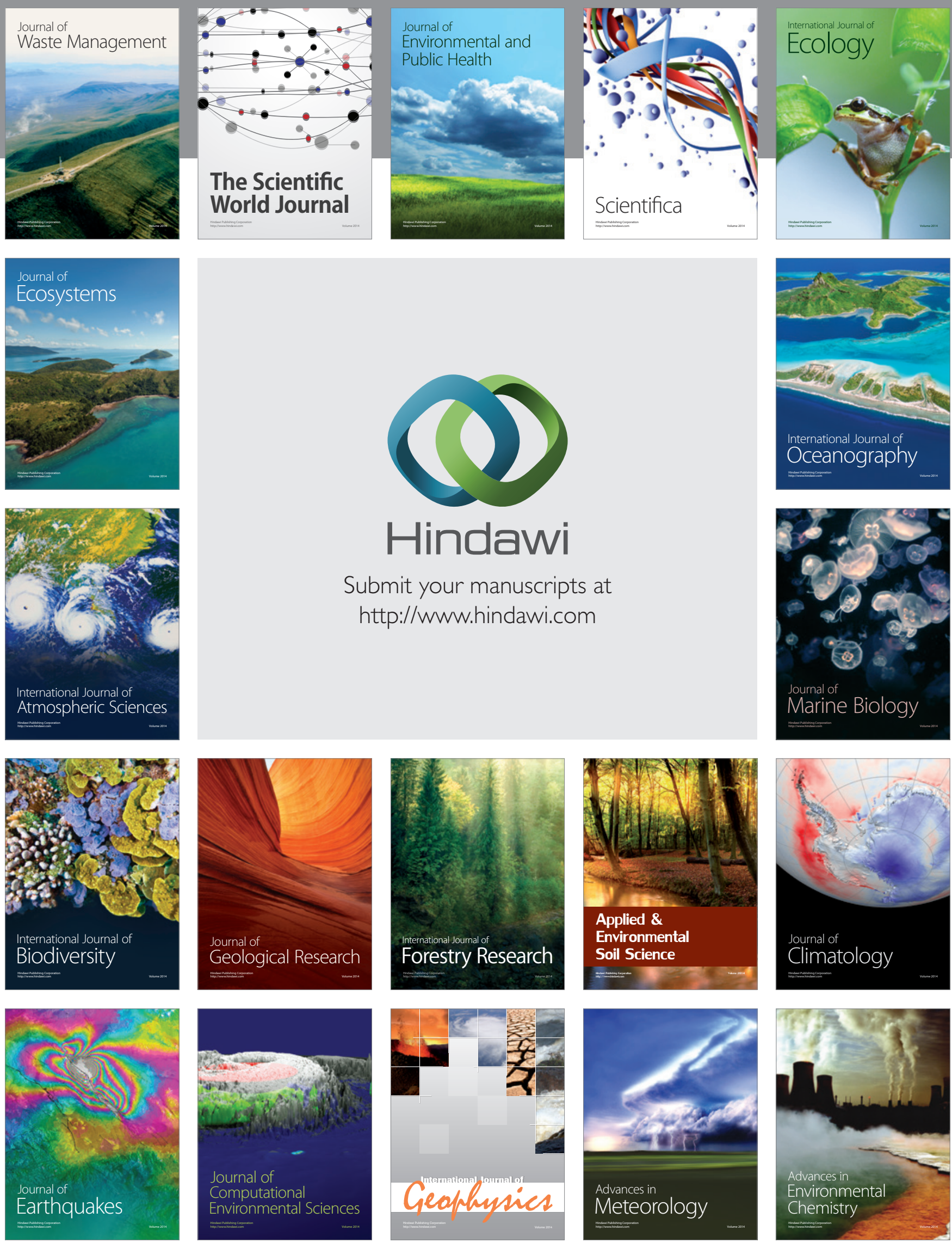